\title{
Comparative Effect of Cooperative Learning on Students' Performance in Mechanics Concepts: A Case of Two Secondary Schools in Berekum Municipality, Ghana
}

\author{
Eric Appiah-Twumasi ${ }^{1}$, Victor Antwi ${ }^{2}$, Ishmael Kwesi Anderson ${ }^{3}$, Nelly Sakyi-Hagan ${ }^{4}$ \\ ${ }^{1}$ Science Department, Berekum College of Education, Berekum, Ghana \\ ${ }^{2,3}$ Department of Physics Education, University of Education, Winneba \\ ${ }^{4}$ Department of Integrated Science Education, University of Education, Winneba \\ *Corresponding author: maamekuumah@yahoo.com
}

\begin{abstract}
The study sought to establish differences in the effect of cooperative learning strategy with and without the instructional manual on the Senior High School students' performance in Mechanics concepts in Physics in the Berekum Municipality, Ghana. The research design employed in this study was the experimental using the pretest and posttest equivalent control group design. A sample of 93 SHS 2 students, drawn from two intact classes was used. An instrument known as Mechanics Concepts Test (MCT) was employed in data gathering. Mean score, standard deviation; t-test, mean gain and effect size analysis were used to answer the research questions, while the independent sample $t$-test was used to test a hypothesis. The results revealed that students taught using the cooperative learning strategy with the instructional manual performed significantly better in the Mechanics Concepts Test (MCT) than those taught using the cooperative learning strategy only. Therefore, it is recommended that physics teachers should use the cooperative learning strategy along with the instructional manual in order to enhance the performance of students in secondary schools.
\end{abstract}

Key words: Cooperative Learning; Instructional Manual, performance, mechanics, physics, Ghana

\section{Introduction}

Physics is an important academic subject to every society. This is due to the fundamental role it plays in modern scientific and technological developments. However, students' performance in the subject at the national and international examinations has been relatively low. For example, the West African Examinations Council reported that in the year 2006 , only $12.5 \%$ of the total candidates obtained grades between $\mathrm{A} 1$ to $\mathrm{C} 6$ in Physics in the West African Senior School Certificate Examination. In 2012 and in a similar examination, the percentage was 28.1 (WAEC 2006; 2012). In the executive summary of the Trends in International Mathematics and Science Study (TIMSS) for 2007 by Anamuah-Mensah, Mireku and Ghartey-Ampiah (2008), it was noted that the overall performance in the Ghanaian Junior High School (JHS) 2 science test was very low. In all the four science content domains (Biology, Physics Chemistry and Earth Science) the Ghanaian JHS 2 students' performance was statistically below the TIMSS scale average of 500 , indicating that the students were very weak in all the four domains. The mean score of 276 in physics particularly, was the least performed in all the domains. Analysis of the WASSCE results of science students over the years showed that students' performance in Physics in Berekum Municipality confirmed the national and international poor trends (Field survey conducted by researchers, 2018).

Some physics concepts and theories are perceived to be abstract and therefore appear difficult for students to comprehend. This perception might be a 
contributing factor to students' low performance in the subject. In response to this gap, studies show that cooperative learning strategies have the potential to improve students' performance in any science subject including physics (Ho \& Boo, 2007; Akinbobola, 2009; Zakaria, Chin \& Daud, 2010). Therefore, the researchers in this study used the cooperative learning strategy and the instructional manual to measure the performance of students in mechanics concepts.

The study was guided by the following research questions:

1. What is the effect of the use of the cooperative learning strategy only on students' performance in mechanics concepts?

2. What is the effect of the use of the cooperative learning strategy with the instructional manual on students' performance in mechanics concepts?

3. What is the difference in mechanics concepts performance between using the cooperative learning instructional strategy only and using the cooperative learning instructional strategy with the instructional manual?

A following null hypothesis was formulated from the third research question: There is no significant difference in mechanics concepts performance between using the cooperative learning instructional strategy only and using the cooperative learning instructional strategy with the instructional manual.

The results of this study will inform physics teachers and teachers of other subjects in secondary schools about the need to prepare comprehensive instructional manuals to guide students through the cooperative learning strategy. Consequently, teachers will be able to shift from the traditional methods of teaching Physics and adopt the cooperative learning strategy which will help students to improve their performance in Physics.

\section{Related Literature and Studies}

This section presents literature on various concepts including the concept of cooperative learning, types of cooperative learning, challenges in using cooperative learning, relevance of cooperative learning and importance of instructional manuals.

\section{The Concept of Cooperative Learning}

Cooperative learning is one of learning strategies that can enhance learners' understanding of science and physics concepts. This strategy is different from the self-centred learning, which focuses mainly on individual learners learning independently. Cooperative learning is a successful instructional strategy in which small groups with students of diverse abilities use a variety of learning activities to improve the learning experiences (Arra, Antonio, \& Antonio, 2011; Nnorom, 2015). According to Wendy (2005), cooperative learning is the umbrella term for a variety of educational approaches involving joint intellectual effort by students and teachers together. It requires a small number of students to work together on a common task, supporting and encouraging one another to improve their learning through interdependence and cooperation with one another (Larry \& Hartman, 2002).

According to Abass (2008), cooperative learning is a method of teaching and learning in which students work together to explore a significant question or create a meaningful project. Felder and Brent (2007) also defined the term as a situation where students work in teams on assignments or projects under a condition in which certain criteria are satisfied. The cooperative learning groups usually comprise of two to five students which allows everyone to participate in a clearly designed task (Wendy, 2005; Sarah \& Cassidy, 2006). In cooperative learning, students must be responsible for their own learning and for the success of the other group members (Slavin, 2011). In other words, students must ensure that each member in the group completes tasks and achieves the intended academic outcomes.

Altun (2015) noted that the lesson cannot be cooperative structured if students do not "swim together" in the group during the learning processes and activities. Therefore, in cooperative learning, if team members are not dependent on each other or fail to have mutual interest in working together to complete the tasks, the success of the team will decrease. Hence, if any group member fails to complete his or her learning task, all the other group members will suffer the effect of that member's action. Therefore, cooperative learning includes any form of instruction in which students work together for a purpose.

\section{Types of Cooperative Learning}

According to Johnson, Johnson and Holubec (2008), there are three types of cooperative learning: formal, informal and cooperative base groups: 


\section{Formal Cooperative Learning}

The formal cooperative learning groups consist of students working together to achieve shared learning goals and jointly complete specific tasks or assignments. They are structured through preinstruction decisions, the cooperative structure, proper monitoring, intervention to improve teamwork, evaluation of students' learning and appropriate group functioning (Adebayo, 2014).

\section{Informal Cooperative Learning}

The informal cooperative learning has to do with students working together to achieve a learning goal in temporary ad-hoc groups that last from a few minutes to one class period. During a lecture or demonstration, the informal cooperative learning can be used to focus student's attention on the material to be learned. The teachers are expected to set a conducive mood and set expectations as to what will be covered in the class session. They also need to activate students' cognitive process and rehearse the material being taught, leading them to summarize what was learned, proceed to the next session and provide closure to the instructional session (Ahmed \& David, 2019).

\section{Cooperative Base Groups}

According to AgwuUdu (2017), cooperative base groups are long-term and heterogeneous with stable membership. Membership primary responsibilities include ensuring that all learners are making good academic progress, holding each other accountable for striving to learn, providing each other with support as well as encouraging and assisting in completing assignments. The teacher's role in the cooperative base groups includes forming heterogeneous groups of four or three members, scheduling a time when members will regularly meet to create specific agendas, ensuring that the basic elements of effective cooperative groups are implemented and having students contribute toward the effectiveness of their base groups.

\section{Challenges in Cooperative Learning}

Teachers and students are likely to face various challenges in the cooperative learning strategy. Slavin (1995) noted that if activities are not properly constructed, cooperative learning methods can allow "free rider" effect, in which some group members do all or most of the work while others remain inactive. Slavin added that, the "free rider" effect is most likely to occur when the group has a single task, especially when they are asked to hand over a single report, to complete a single worksheet or to produce one project as a group. Distribution of responsibility or roles is another difficulty whereby there could be a situation in which some group members may ignore other learners who are perceived to be less skillful or less knowledgeable (Gambari, 2016).

Zakaria and Iksan (2006) further stated that the main challenges which arise in using the cooperative learning strategies include the following:

1. A need to prepare extra materials for class use: This requires a lot of work by the teachers and therefore, it is a burden for them to prepare new materials to cater for all the groups.

2. Fear of the loss of content coverage: Cooperative learning methods often take longer time than lecture method such that some teachers conclude that it is a waste of time.

3. Some teachers do not trust students in acquiring knowledge by themselves. They think they must tell their students what and how to learn and that only the teachers have the knowledge and expertise.

4. Lack of familiarity with the cooperative learning methods: Cooperative learning is new to some teachers. Therefore, they may need some time to be familiar with the new method before using it.

5. Perceived students' lack of skills to work in group: Some teachers are often concerned with students' participation in group activities. They think that students lack the necessary skills to work in group.

6. Evaluating students' group work can be challenging in the face of students' preferences for full control over their individual grades and particularly in the era where institutions heavily rely on individual grading procedures.

However, Pantiz (2003) provided the following techniques which to some extent address the challenges in the use of the cooperative learning strategy:

1. Teachers should do constant observations during group work

2. Teachers should consider using group grading for projects 
3. Students should grade each other or evaluate the level of contribution made by each member to a team project

4. Teachers should give extra credit when groups exceed their previous grade or when individuals within the group exceed their previous performance.

5. Teachers should use mastery approach whereby students may retake tests after receiving extra help from their groups or the teacher.

6. The use of quizzes, exams or assignments should be considered to ensure individual accountability.

\section{Relevance of Cooperative Learning}

Cooperative learning is a student-centred instructional approach, which harnesses students' ideas by bringing students' experiences, points of view, feelings and problems into the lesson by making the students the primary point of reference. A completely student oriented lesson is always initiated by asking students questions and assigning specific roles to them on the content to be taught and their answers and dispositions would become the focus of the lesson (Ajaja \& Eravwoke, 2010). Borich (2004) asserted that the surest way to enhance students' interest and to encourage positive attitude and feeling towards the subject is through the use of cooperative learning strategies.

The impact of cooperative learning on students' academic achievement was investigated by Effandi (2003) cited by Effandi and Zanaton (2006). This study examined how cooperative learning affects students' achievement and problem solving skills. The experimental group was instructed using cooperative learning while the control group was instructed using the traditional lecture method. The cooperative learning group instruction showed significant better results in Mathematics achievement and problem solving skills. The effect size was moderate and therefore practically meaningful. The study also revealed that, students taught by cooperative learning had a favorable response towards group work and the conclusion was that utilization of cooperative learning methods is a preferable alternative to traditional instruction (Caper \& Terim, 2015; Olabiyi \& Awofala, 2019).

Schwarz, Neuman and Biezuner (2000) presented a classroom study showing that two students working together can make learning gains even when both students entered the peer learning situation with low levels of competence. They further indicated that the thrust of the research on peer learning shows that when peers engage in dialogues and discussions that are relevant to both the task at hand and to initial misconceptions, cognitive gains can result from the peer interactions. A study by Ajaja and Eravwoke (2010) which tested the effect of cooperative learning on students' performance had a conclusion that students usually have significant higher achievement test scores in cooperative learning group than in traditional classrooms.

Felder and Brent (2007) indicated that cooperative learning is superior for promoting metacognitive thought, persistence in working towards a goal, transfer of learning from one setting to another, time on task and intrinsic motivation. Their conclusion was that students who score in the $50^{\text {th }}$ percentile when learning competitively would score in the $69^{\text {th }}$ percentile when taught cooperatively. Affective outcomes were also improved by the use of cooperative learning. Compared to students involved in individual or competitive learning environments, cooperatively taught students exhibited better social skills and higher self-esteem. From these perspectives it is evident that the use of cooperative learning yields better results than the traditional lecture method with regard to students' performance in a particular subject (Caper \& Terim, 2015).

\section{Importance of Instructional Manuals}

Instructional manual is a book or booklet of instruction, designed to improve the quality of a performed task. An instructional manual (also called course manual) may form an important part of a formal training or learning in the classroom. For example, it may help to ensure consistency in the presentation and the delivery of content. It may also ensure that all training information on skills, processes and other information necessary to perform tasks are together in one place. According to Amedeker and Taale (2011), the course manual helps students to approach their learning with the appropriate strategies, to give students resources or materials that will help them prepare well ahead of lessons, challenge students to improve their abilities to search for information and to think critically.

Usually, the course manual is the student's first port of call, especially when seeking information about a particular course that the student is beginning to 
undertaken. It is therefore imperative to include all that the students need to know about the course and the lecturer concerned (Lanigan, 2010). For example, the general information about the course (course code, title, the name, phone number/email and office of the lecturer, the number of credit hours, when and where the course will run should be included in the general information. There should also be a short description of what the students expect to learn. The learning objectives, the course structure, quizzes, assignments and examination schedules should be spelt out in the course manual. Also, the pages of the literature the students must read and questions/tasks for students to respond should be indicated in the course manual.

\section{Research Methodology}

This section presents about the methodology used to conduct the study. It includes such concepts like research design, population and sampling procedures, research instruments, validity and reliability of research instruments, data collection procedures and data analysis procedures.

\section{Research Design}

This study employed an experimental, nonrandomized pretest-treatment-posttest study design with two equivalent intact classes using formal cooperative learning. This design was used because of the following reasons. It was appropriate because students prior to the study had some knowledge about the aspect of the mechanics concepts to be treated in the study. Hence the pretest was used to assess this prior knowledge. The choice of the experimental design was also informed by the fact that at the SHS level, students are put into specific classes to do specific programs. Hence intact classes were used in order not to disorganize classes assigned to students through randomization of students for this research. Another reason to use the experimental design with the pretest and posttest approaches was that experimental designs seek to demonstrate causality between a treatment and outcome. The experimental design divided the sample into two instructional groups where group one was instructed using cooperative learning only CLO (control group) and the other group was taught using the cooperative learning strategy with the instructional manual (CLWIM (experimental group). The utilization of the cooperative learning served as a fixed or constant study variable within the two groups. The main independent variables were cooperative learning strategies and the instructional manual. The dependent variable was students' performance in Mechanics Concept Test (MCT).

\section{Population, Sampling and Sampling Procedure}

The target population for the study comprised all the SHS Science and Technical students in the Berekum Municipality. The accessible population for the study however, comprised of two Senior High Schools. For anonymity, researchers referred to the schools as SHS A and SHS B, which are about three kilometers apart. A total of 93 male and female, $2^{\text {nd }}$ year Science students were used in the study. The participants were between 15 to 20 years old and were composed into two groups. The first group of 48 students was the experimental group (SHS A) whereas the second group of 45 students was the control group (SHS B). Participants in the study were all of similar educational background as they had all passed the Basic Education Certificate Examination (BECE) at the Junior High School (JHS) level. Also, they had some basic knowledge of the concepts of the mechanics topics as they had been introduced to it at the SHS one.

Second year students were purposively selected for the study because mechanics concepts considered are taught during the second year of the SHS science program as it forms part of the SHS 2 elective physics syllabus. In the Experimental Group (SHS A) of forty-eight (48) students, twelve (12) were girls and the remaining thirty six (36) were males. In the Control Group (SHS B) of forty-five (45) students, thirty-four (34) were males while eleven (11) were females. The Experimental Group had 12 mixed ability and heterogeneous (e.g. male and female) groups. There were four (4) members in each group formed. These groups were maintained throughout the seven weeks of the treatment period. They were instructed using cooperative learning strategies coupled with the instructional manual. In the Control Group), 11 mixed ability and heterogeneous groups were formed. There were four (4) members with exception of only one of the groups which had five members and these groups were also maintained throughout the treatment period.

\section{Research Instruments}

Two research instruments were used to collect data: the instructional manual and Mechanics concept test (MCT.) These instruments were prepared by the Researchers and were pilot-tested before they were used in the field. 


\section{The Instructional Manual}

The instructional manual was a useful treatment instrument in the research data collection. It ensured consistency in presentation and the delivery of the teaching and learning process in the Experimental Group. It also ensured that all instructional information on skills, processes and other information (like reference books) necessary to perform tasks were together on one place for the students to access. The instructional manual guided the students about what to do before and after every lesson. It consisted of seven weekly activities designed to take participants through in the treatment phase of the research.

Table 1: Mechanics Concept Test (MCT) Content and Question Selection.

\begin{tabular}{ll}
\hline Concept & Question(s) \\
\hline Circular Motion & $(17), 1 \mathrm{a}, 1 \mathrm{~d}$ \\
Angular velocity & $2 \mathrm{a}(\mathrm{i})$ \\
Linear velocity & $2,3,14$ \\
Centripetal force & $12,(2 \mathrm{~b})$ \\
Banking of roads & $7,1 \mathrm{c}$ \\
Relationship between $v, r, w$ & 9 \\
Relationship between $\quad \mathrm{a}, \mathrm{r}, \mathrm{w}$ & 5 \\
Maximum acceleration & \\
Oscillatory motion & $1,8,(13)$ \\
Simple pendulum & $10,11,1 \mathrm{~b}, 2 \mathrm{a}$ (ii) \\
$\begin{array}{l}\text { Period of oscillation } \\
\text { Gravitational force }\end{array}$ & $4,11,16$ \\
Newton law of gravitation & 6 \\
Escape velocity & 15 \\
Geostationary Satellites & \\
$v=$ Linear velocity, $r=$ radius, $a=$ linear acceleration and $w=$ angular velocity \\
Parenthesis means that other components are significantly involved in the Question
\end{tabular}

\section{Mechanics Concept Test (MCT)}

The MCT comprised three main topics in mechanics. These are the circular motion, oscillatory motion and gravitational force. Similar set of questions was used as pretest and posttest. The pretest was used to assess students' prior knowledge concerning those mechanics concepts under consideration. The posttest was used to collect data for the study to measure the effectiveness of the instructional manual and cooperative learning strategies variables for the study. The test consisted of 20 items. The mechanics concept test was made up of 18 multiple-choice and two theory questions. Table 1 shows the structure of the MCT.

\section{Validity and reliability of the Instrument}

The self-designed MCT was given to some experienced physics lecturers and teachers for their comments and suggestions. The purpose of this exercise was to assess each item's content validity, accuracy and format.

To determine the reliability of the instruments, the test items were field pilot-tested at SHS C located in the same study area with fifteen (15) students. The 15 students were made to answer and re-answer the same test under the same conditions within five days interval. Their answers were compared and it was observed that students gave similar answers. This showed that the reliability of the questions in the test was acceptable and for this reason internal consistency of the instruments was ensured.

\section{Data Collection Procedure}

Data collection procedure had three phases: the Pre-Treatment Phase, the Treatment Phase and the Post-Treatment Phase.

\section{Phase 1: Pre-Treatment phase}

Formal permission was sought from the Headmasters of the two schools selected for the study by the researchers. The Physics teachers in these schools were also duly notified. The use of cooperative learning and instructional manual and its benefits were explained to the students. The researchers also took students through the instructional manual and how it would be used. The next stage of the pre-treatment phase was the formation of heterogeneous cooperative base groups. Once the groups were formed, students were given one week to go through the instructional manual and locate the reference books stated in the 
instructional manual. The researchers also made photocopies of portions of books stated in the reference section on the instructional manual which were not in the libraries. The last stage of the pretreatment was administering the test.

Table 2: Treatment Phase Processes for the Experimental Group

\begin{tabular}{ll}
\hline PHASE & TEACHER / STUDENTS ACTIVITIES \\
\hline $\begin{array}{l}\text { Phase }-1 \\
\text { Teacher clarified goals and motivated } \\
\text { Phase }-2 \\
\begin{array}{l}\text { Teacher presented information and/or } \\
\text { materials }\end{array}\end{array}$ & $\begin{array}{l}\text { Teachers went over goals for the lesson while students were } \\
\text { listening. }\end{array}$ \\
$\begin{array}{l}\text { Teachers presented lessons in the form of lecture, illustrations } \\
\text { and discussion on each week's activities reflecting on the } \\
\text { instructional manual and the lesson notes while students were } \\
\text { Assessment }-3\end{array}$ & $\begin{array}{l}\text { listening. } \\
\text { Phase }-4\end{array}$ \\
$\begin{array}{l}\text { Teaphervision } \\
\text { to the groups after every lesson }\end{array}$ \\
$\begin{array}{l}\text { Phase }-5 \\
\text { Evaluation } \\
\begin{array}{l}\text { Phase }-6 \\
\text { Conclusion }\end{array}\end{array}$ & $\begin{array}{l}\text { Teachers supervised students to answer the questions. } \\
\text { They also assessed each member's performance, marked, } \\
\text { graded and did corrections with students. }\end{array}$ \\
\hline
\end{tabular}

Table 3: Treatment Phase Processes for the Control Group

\begin{tabular}{|c|c|}
\hline PHASE & TEACHER / STUDENTS ACTIVITIES \\
\hline \multicolumn{2}{|l|}{ Phase - 1} \\
\hline Teacher clarified goals & $\begin{array}{l}\text { The teacher went over goals for the lesson while students were } \\
\text { listening. }\end{array}$ \\
\hline \multicolumn{2}{|l|}{ Phase - 2} \\
\hline $\begin{array}{l}\text { Teacher presented the information and/or } \\
\text { materials }\end{array}$ & $\begin{array}{l}\text { The teacher presented lesson in the form of lecture, } \\
\text { illustrations, and discussion on each week's activities reflecting } \\
\text { the teaching notes. }\end{array}$ \\
\hline \multicolumn{2}{|l|}{ Phase - 3} \\
\hline Evaluation/assessment & $\begin{array}{l}\text { The teacher gave end of lesson quizzes/ assignments and } \\
\text { exercises to the groups after every lesson. }\end{array}$ \\
\hline \multicolumn{2}{|l|}{ Phase -4} \\
\hline Supervision & The teacher supervised students to answer the questions. \\
\hline \multicolumn{2}{|l|}{ Phase - 5} \\
\hline Evaluation/assessment & $\begin{array}{l}\text { The teacher assessed each member's performance, marked, } \\
\text { graded and did correction with students. }\end{array}$ \\
\hline \multicolumn{2}{|l|}{ Phase - 6} \\
\hline Conclusion & $\begin{array}{l}\text { The teacher concluded the lesson by summing up the main } \\
\text { points using the NHT. cooperative learning technique }\end{array}$ \\
\hline
\end{tabular}

\section{Phase 2: Treatment Phase}

Phase two involved the implementation of the procedure/treatment that the researchers had designed to use in the course of their teaching. The students played active roles throughout the treatment phase in both the experimental and the control groups. Some of their roles at this point were for them to work together or cooperate with others through listening to one another, questioning, keeping records of their work and the progress as well as assuming personal responsibility of being involved in the group.

The experimental group was taught by the researchers for the seven weeks of the interventional phase, while the control group was taught by the physics teachers in their school. To 
ensure uniformity in the teaching and learning process, the researchers and the physics teachers used the same teaching notes, same exercises and assignments for the two groups. The steps involved in the treatment phase of the experimental group (CLWIM) are shown in Table 2.

\section{Phase 3: Post-Treatment Phase}

The seventh or the last week was used for the administration of the post-treatment test. During this phase, the researchers with the help of the Physics teachers in the selected schools administered the post-treatment test to both the experimental and the control groups. The researchers marked and scored the students scripts. Progress in the students' lesson was observed and monitored.

\section{Data Analysis Procedure}

Data analysis was carried out step by step from the beginning to the end of the study. The data was analysed using SPSS version 16.0. According to Awanta and Asiedu-Addo (2008), the Statistical Package for Social Science (SPSS) is by far one of the best known and widely used software for the statistical analysis of social sciences data in educational research.
Descriptive statistics, t-test and test-retest reliability were conducted on the data. Descriptive statistics tools such as mean and standard deviation were carried out to measure trends in the cooperative learning strategies and the instructional manual.

T-test was used to explore the statistical differences between the performances of the two groups prior to study. The accepted $p<.05$ level of probability was used as the basis to deciding whether statistically significant differences between the performances of students in the two groups existed after exposure to the cooperative learning and the instructional manual.

\section{Results and Discussion}

This section presents results and then discusses findings in the light of literature reviewed.

\section{Groups Entry Characteristic Analysis}

The experimental group $(\mathrm{N}=48)$ and the control group $(N=45)$ were constituted of form two equivalent intact classes. T-test was used to determine whether there is a significant difference between the experimental and control groups prior to the introduction of the intervention. The results of the entry characteristics test are presented in Table 4.

Table 4: Entry Characteristics on Performance for the Groups

\begin{tabular}{llllll}
\hline Group & $N$ & Mean & $S D$ & $t$-value & $p$-value \\
\hline Experimental (SHS A) & 48 & 4.46 & 1.3 & 0.22 & $0.82^{*}$ \\
Control (SHS B) & 45 & 4.40 & 1.19 & & \\
\hline
\end{tabular}

*not significant, $\mathrm{p}>.05$

Table 5: Pretest and Posttest Mean Scores for the Control Group

\begin{tabular}{lllll}
\hline Group & N & Pretest Mean & Posttest Mean & Mean Gain \\
\hline Control (SHS B) & 45 & $22.87(6.75)$ & $26.84(5.59)$ & 3.97 \\
\hline
\end{tabular}

Standard Deviation in parenthesis

In Table 4.0, the mean and standard deviation scores of the experimental group were determined as 4.46 and 1.30 respectively in entry characteristics test conducted before the treatment. In the control group, the mean and standard deviation scores were determined as 4.40 and 1.19 respectively in the same entry characteristics test conducted before treatment. No statistically significant difference $[p=0.82)]$ was observed in the independent-samples t-test for the two groups before the intervention. The mean score of the experimental group was almost within the same range as the mean score of the control group. This indicates that the experimental and the control groups were equivalent in performance before the treatment. Hence any change in groups' performance in MCT after the treatment may be attributed to the treatment used.

\section{Results}

The results and analysis of the data collected were guided by the three research questions.

RQ 1: What is the effect of the use of the cooperative learning strategy only on students' performance in mechanics concepts?

The effect of cooperative learning on students' performance in mechanics concepts was 
determined using descriptive statistics of the pretest and posttest scores of the control groups' performance in the MCT. Table 5 shows the mean, the standard deviation and the mean gain for the control group in the MCT conducted before and after the introduction of the treatment.

Table 5 shows that the control group had pretest and posttest mean scores of $22.87(S D=6.75)$ and 26.84 (SD = 5.59) respectively after being exposed to cooperative learning strategy only. A mean gain of 3.97 was obtained for the control group. Achieving a group average of 26.84 in the post- treatment test compared with 22.78 in the pre- treatment test confirms an improvement in the control group. Also reduced standard deviation ( $S D=5.59$ ) in the posttreatment test compared with standard deviation $(S D=6.75)$ in the pre- treatment test shows smaller variability in the scores of the individual students in the performance of the control group. Therefore, the cooperative learning strategy without the use of the manual had a positive effect on the students' performance in the mechanics concepts.

RQ 2: What is the effect of the use of the cooperative learning strategy with the instructional manual on students' performance in mechanics concepts?

The effect of the cooperative learning strategy on students' performance in mechanics concepts was determined using descriptive statistics of the pretest and posttest scores of the experimental groups. Table 6 shows the mean, standard deviation and mean gain of the experimental group in the MCT conducted before and after the introduction of the treatments (i.e. the use of the cooperative learning and the instructional manual).

Table 6: Pretest and Posttest Mean Scores for the Experimental Group

\begin{tabular}{lllll}
\hline Group & $\mathrm{N}$ & Pretest Mean & Posttest Mean & Mean Gain \\
\hline Experimental (SHS A) & 48 & $22.97(6.66)$ & $30.17(6.81)$ & 7.20 \\
\hline *standard deviation in parenthesis & & &
\end{tabular}

*standard deviation in parenthesis

Table 7: Pretest and Posttest Mean Scores for the Two Groups

\begin{tabular}{lllll}
\hline Groups & $\mathrm{N}$ & Pretest Mean & Posttest Mean & Mean Gain \\
\hline Experimental (SHS A) & 48 & $22.97(6.66)$ & $30.17(6.18)$ & 7.20 \\
Control (SHS B) & 45 & $22.87(6.75)$ & $26.84(5.59)$ & 3.97 \\
Mean Difference & & 0.1 & 3.33 & \\
\hline
\end{tabular}

*standard deviation in parenthesis

Table 6 shows that the experimental group had pretest and posttest means scores of 22.97 (SD = $6.66)$ and 30.17 (SD $=6.81$ ) respectively after being exposed to cooperative learning strategy through the instructional manual. Respondents had a mean gain of 7.20 after using cooperative learning strategies with the instructional manual to teach the experimental group. Achieving a group average of 30.17 in the post- treatment test compared with the average of 22.97 in the pre- treatment test confirms an improvement in the experimental group performance after using the cooperative learning through the instructional manual.

$\mathrm{RQ}$ 3: What is the difference in the performance of students instructed using the cooperative learning strategy only and the cooperative learning strategy with the instructional manual?

To find out the difference in the performance of students taught using the cooperative learning strategy only and students taught using the cooperative learning through the instructional manual, descriptive statistics were computed and used to determine the difference in the performance between the groups. Table 7 shows the mean, standard deviation, mean gains and mean difference of the control and the experimental groups in the MCT conducted before and after the introduction of the treatments.

Table 7 shows that the experimental group pretest and posttest mean scores were 22.97 (SD = 6.66) and 30.17 (SD =6.81) respectively while the control group had the pretest and posttest scores of 22.87 $(S D=6.75)$ and $26.84(S D=5.59)$ respectively. The mean gain for the experimental group was 7.20 while the mean gain for the control group was 3.97. These results revealed that students taught using the cooperative learning strategy with the instructional manual performed better in the mechanics concepts test than those taught using the 
cooperative strategy without the instructional manual. To estimate the extent of difference between the two groups, an effect size analysis was carried out using Cohen's $(d)$ index which involved comparing the mean scores of the two groups and dividing them by the standard deviation. The results of $d$ are presented in Table 8 .

Table 8: Magnitude of Effect for the Treatments

\begin{tabular}{lllll}
\hline Group & $\begin{array}{l}\text { Posttest } \\
\text { Mean }\left(\mathrm{M}_{2}\right)\end{array}$ & Pretest Mean $\left(\mathrm{M}_{1}\right)$ & Mean Diff. $\left(\mathrm{M}_{2}-\mathrm{M}_{1}\right)$ & $d$ \\
\hline Experimental (SHS A) & $30.17(6.81)$ & $22.97(6.66)$ & 7.2 & 1.07 \\
Control (SHS B) & $26.84(5.59)$ & $22.89(6.75)$ & 3.97 & 0.64 \\
\hline
\end{tabular}

*standard deviation in parenthesis

Table 9: Inferential Statistics for Groups Mean Score Difference for the Posttest

\begin{tabular}{lccccc}
\hline Groups & $\mathrm{N}$ & Mean & SD & t-value & p-value \\
\hline Experimental (SHS A) & 48 & 30.17 & 6.81 & 2.54 & $0.012^{*}$ \\
Control (SHS B) & 45 & 26.84 & 5.59 & & \\
\hline *significant, $\mathrm{p}<.05$ & & & & &
\end{tabular}

From Table 8, the effect size of the experimental group was 1.07. This represents large effect size comparing to Cohen's $d$ indexes in Appendix A. Also, effect size estimated for the control group was 0.64 . This represents a medium effect size. Using the Magnusson's interpretation, 1.07 Cohen $d$ obtained for the CLSWIM means that, about $86 \%$ of the mean score for students taught using the instructional manual is above the mean score for student taught without using the manual. Moreover, there is about $78 \%$ chance that a student picked at random from the CLSWIM group will have higher score than a student picked at random from the CLSO group. The results indicate that, using cooperative learning strategies through the instructional manual ( $d=1.07$ ) has greater effect on students' performance as compared to using cooperative learning strategies only $(d=0.64)$. This signifies that there is a substantial difference in the two methods of teaching.

To determine whether the difference in the performance between the experimental group and the control group were statistically significant, research question three was formulated into the following null hypothesis and tested.

$\mathrm{H}_{01}$ : There is no significant difference in performance between students instructed using the cooperative learning strategy only and those instructed using the cooperative learning strategy with the instructional manual.

To test this hypothesis, an independent sample $t$ test was performed and the results are presented in Table 9.

The results show that there is significant difference between the post-intervention test scores of students instructed using the cooperative learning strategy with instructional manual $(M=30.17, S D=$ 6.81) and those instructed using the cooperative learning strategy only $(M=26.84, S D=5.59)$. $[t=(91)$ 2.54, $p=.012]$. Hence the null hypothesis was rejected.

\section{Discussion of Findings}

Research Question 1:

What is the effect of the use of cooperative learning strategy only on students' performance in mechanics concepts?

In the control group, the treatment (Cooperative learning strategy) was found to have significant effect on the students' performance in the test instrument used (MCT). Students in the control group after being exposed to cooperative learning strategies scored relatively better in the postintervention test used compared with the preintervention test results of the same test. 
The higher level of performance observed in the cooperative learning based instruction agrees with the findings of Schwarz, Neuman and Biezuner (2000) who concluded that two students working together can make learning gains even when both students entered the peer learning situation with low levels of competence. Schwarz, Neuman and Biezuner (2000) further indicated that when peers engage in dialogues and discussions that are relevant to both the task at hand and to initial misconceptions, cognitive gains can result from the peer interactions. Therefore, this study confirms the attributes of the cooperative learning in enhancing the performance.

The findings also are in agreement with those by Ajaja and Eravwoke (2010) that tested the effect of cooperative learning on students' performance who reported a significant higher achievement test scores of students in the cooperative learning group than those in the traditional classroom. The findings support the campaign to shift from the traditional ways of teaching to embrace the cooperative learning strategy.

RQ2: What is the effect of the use of the cooperative learning strategy with the instructional manual on students' performance in mechanics concepts?

Amedeker and Taale (2011) suggested that the instructional manual helps students to approach their learning with the appropriate strategies, gives students resources or materials that help them prepare well ahead of lessons and challenges students to improve their ability and to think critically.

RQ3: What is the difference in the performance of students instructed using the cooperative learning strategy only and the cooperative learning strategy with the instructional manual?

Findings with respect to research question three showed that there was a substantial difference between students instructed using the cooperative learning strategy only and those instructed using the cooperative learning strategy with the instructional manual. The findings do not support the null hypothesis that there is no significant difference in the performance between students taught using the cooperative learning strategy only and those instructed using the cooperative learning strategy with the instructional manual. Therefore, the null hypothesis is rejected.
Effect size analysis result of the control group $(d=0.64$, representing a moderate effect size) confirms findings of the study conducted by Johnson and Johnson (2013) who reported a $d=0.76$, representing a moderate effect size for students who were engaged in the cooperative learning as against competitor's learning. The findings also confirm the effect size reported by Kai-Ti and TzuHua (2012) and Magnusson (2014), who reported that effect size of cooperative learning strategy on achievement, attitudes and perception were 0.54, 0.15 and 0.18 respectively. The results are also in harmony with those of Caper and Terim's (2015) who compiled experimental studies from 1988 to 2010 to examine the influence of the cooperative learning method as compared with that of traditional methods on mathematics achievement. The study reported the effect size of 0.59 for cooperative learning on academic achievement.

\section{Conclusions}

The study concludes that cooperative learning strategies used had proven to be an effective approach to Physics students at the SHS level. Students' performance is enhanced when they work together cooperatively than when they work individually. Moreover, using the cooperative learning strategy with the instructional manual has more positive effect in improving students' performance than using the cooperative learning strategy only.

\section{Recommendations}

Based on the findings of the study and conclusions drawn, the researchers recommend that physics teachers should use the cooperative learning along with the instructional manual to realize enhancement of students' performance in Physics. They also need to develop the cooperative learning skills and knowledge in order to enhance the quality of the teaching and learning sessions. Finally, as the effects of the instructional manual cannot be overlooked, teachers should be encouraged to use the instructional manual for realization of students' improved performance.

\section{Reference}

Abass, F. (2008). Cooperative learning and motivation. Retrieved July 17, 2017, from http://leo.aichiac.jp/ golken/bulletin/pdfs/no18/02folkeab ass.pdf 
Adebayo, S. A. (2014). Comparative study of effectiveness of cooperative learning strategy and traditional instructional method in the physics classroom: a case of Chibote Girls Secondary School, Kitwe District, Zambia. European Journal of Educational Sciences, 1(1), 30-41.

AgwuUdu, G. (2017). Comparative effects of individual and cooperative learning instructional strategies on senior secondary school students' academic achievement in organic chemistry. Electronic Journal of Science Education, 22(2), 1-14.

Ahmed, A., \& David S. A. (2019). The input of activity based learning on students' motivation and academich achievement: a study among $12^{\text {th }}$ grade science and environmenst students in a public school in Oman. Science Arena Publications Special Journal of knowledge Management, 4(4), 44-53.

Ajaja, B., \&. Eravwoke, O. (2010). Effects of cooperative learning strategy on junior secondary students achievement in integrated science. Electronic Journal of Science Education, 14(1), 1-18.

Akinbobola, A. O. (2009). Enchancing students' attitude towards Nigerian senior secondary schools physics through the use of cooperative, competative and individualist strategies. Australian Journal of Teacher Education, 34(1),166-167.

Altun, S. (2015). The effect of cooperative learning on students' achievement and views onn the science naad technology course. International Journal of Elementary Education, 7(3), 451-468.

Amedeker, M. K., \& Taale, K. D. (2011). Research Methods in Science Education. Winneba: I.E.D.E, Unversity of Education, Winneba.

Anamuah-Mensah, J.,Mireku, D. K., \& GharteyAmpiah, J. (2008). Trends in International Mathematics and Science Study. LegonAccra: Adwinsa.

Arra, C. T., Antonio, M. D., \& Antonio, M. J. (2011).Students' preferences for cooperative learning instructional approaches: considerations for college tearchers. Journal of Research in Education , 21(115), 114-121.

Awanta, E. K., \& Aseidu-Addo, S. K. (2008). Essential statistical technique in research: for university in education. Accra: Salt ' $\mathrm{N}$ ' Light Publications.

Borich, G. D. (2004). Effective teaching method. New Jersey: Pearson Merrill Prentice Hall.

Caper, G., \& Terim, K. (2015). Efficacy of the cooperative methods on mathematics achievement and attitude : a meta- analysis Research. Retrieved May 14, 2017, from http://www.estp.com.tr

Effandi, Z., \& Zanaton, I. (2006). Promoting cooperative learning in science and mathematics education. Eurasia Journal of Mathematics Education, 3(1), 35-39.

Felder, R. M., \& Brent, R. (2007). Cooperative learning. In P. A. Mabrouk, active learning: models from the analytical sciences (pp. 3454). Washington, D. C.: American Chemical Society.

Gambari, A. I. (2016). Effects of computer-assisted jigsaw ii cooperative learning strategy on physics achievement and retention. Contemporary Educational Technology, 7(4), 352-367.

Ho, F. F., \& Boo, H. K. (2007). Cooperative learning: Exploring its effectiveness in the Physics classroom. Asia-Pacific Forum on Science Learning and Teaching, 8(2),1-27.

Johnson,D., \& Johnson, R. T. (2013). The impact of cooperative learning, competitive and Individualistic learning environments on achievement.In J. Hattie, \& E. Anderman, International Handbook of Students of Achievement (pp. 372-374). New York: Routledge.

Johnson, D., Johnson, R. T.,\& Houbec., E.(2008). Circles of Learning ( $5^{\text {th }}$ ed.). Edina, $\mathrm{MN}$ : Interaction Book Company.

Kai-Ti, Y., \& Tzu-Hua, W. (2012). Interactive whiteboard: effective interactive teaching strategy designs for biology teaching. Retrieved July 28, 2018, from http://intechopen.com/books/elearningengineering-on-job-trainingandinteractive-teaching/interactivewhiteboardeffectinteractiveteachingstrtegy-designsfor-biology-teaching

Lanigan, M. L. (2010). How to Create Effective Training Manuals. Tinley Park, Illinois: Third House, Inc.

Larry, Z., \& Hartman, R.(2002). Cooperative Learning in the secondary schools methathematics classroom: discussion 
theory and contemporary research.

Adolescent Learning and Development Education, 0500A, 1-6.

Magnusson, K. (2014). Interpreting Cohen's ' $d$ ' effect size, an interactive visualization. Retrieved June 12, 2018, from http://rpsychologist.com

Moorberg, C. J., \& Crouse, D. A. (2017). An opensource laboratory manual for introductory undergraduate soil science courses. Natural Science Education, 46, 1- 8.

Nnorom, R. N. (2015). Effect of cooperative learning instructional strategy on senior secondary school students' achievement in biology in Anambra State, Nigeria. International Journal for Cross-Disciplinary Subjects in Education (IJCDSE), Special Issue, 5(1), 24242427.

Olabiyi, O. S., \& Awofala, A. O. A. (2019). Effect of co-operative learning strategy on senior secondary school students' achievement in woodwork technology. Acta Didactica Napocensia; Cluj-Napoca, 12(2), 171-182. DOI:10.24193/adn.12.2.13

Pantiz, T. (2003). Exploring the 7 Principle of Good Understanding. Education as a basis for improving students retention in maths classes. Retrieved February 10, 201, from http://home.capecod.net/ tpaniyz/resume. html

Sarah, M. W., \& Cassidy, J. (2006). Cooperative learning in elementary classrooms. Educational Psychology, 393, 1-5.

Schwarz, B. B., Neuman, Y., \& Biezuner, S. (2000). Two wrong may be a right ... if they argue together. Cognition and Instruction , 18(4), 461-494.
Slavin, R. E. (1995). Cooperative learning: theory, research and pratice $\left(2^{\text {nd }}\right.$ ed.). Boston: Allyn \& Bacon.

Slavin, R. E. (2011). Instruction Based on Cooperation Learning. In R. E. Meyer \& P. A. Alexander (Eds), Handbook of Research on Learning and Instruction (pp. 344-360). New York: Tayor \& Francis.

The West African Examinations Council. ([W.A.E.C.] 2006). General Resume of Chief Examiners' Report, WASSCE, May/June. Retrieved March 28, 2017, from http://www.ghanaweac.org/ExamerWEACM AYJUNE.aspx

The West African Examination Council. ([W.A.E.C.] 2012). General of Resume Chief Examiners' Report, WASSCE, May/June. Retrieved June 21, 2017, from http://www.ghanaweac.org/ExaminerWEAC MAYJUNE.aspx

Wendy, J. (2005). The implementation of cooperative learning in the classroom. Center for Educational Studies, University of Hull, 1-2.

Zakaria, E., Chin, L. C., \& Daud, M. Y. (2010). The effects of cooperative learning on students' mathematics achievement and attitude towards mathematics. Journal of Social Science, 6(2), 272-275.

Zakaria, E., \& Iksan, Z. (2006). Promoting cooperative learning in science and mathematics education: a Malaysian perspective. Eurasia Journal of Mathematics, Science\& Technology Education, 3(1), 35-39. 